Document downloaded from:

http://hdl.handle.net/10251/27847

This paper must be cited as:

Calero Rodriguez, MDP.; Hecht, M.; Martínez Mañez, R.; Sancenón Galarza, F.; Soto Camino, J.; Vivancos, J.; Rurack, K. (2011). Silica nanoparticles functionalised with cation coordination sites and fluorophores for the differential sensing of anions in a quencher displacement assay (QDA). Chemical Communications. 47(38):10599-10601. doi:10.1039/C1CC13039K.

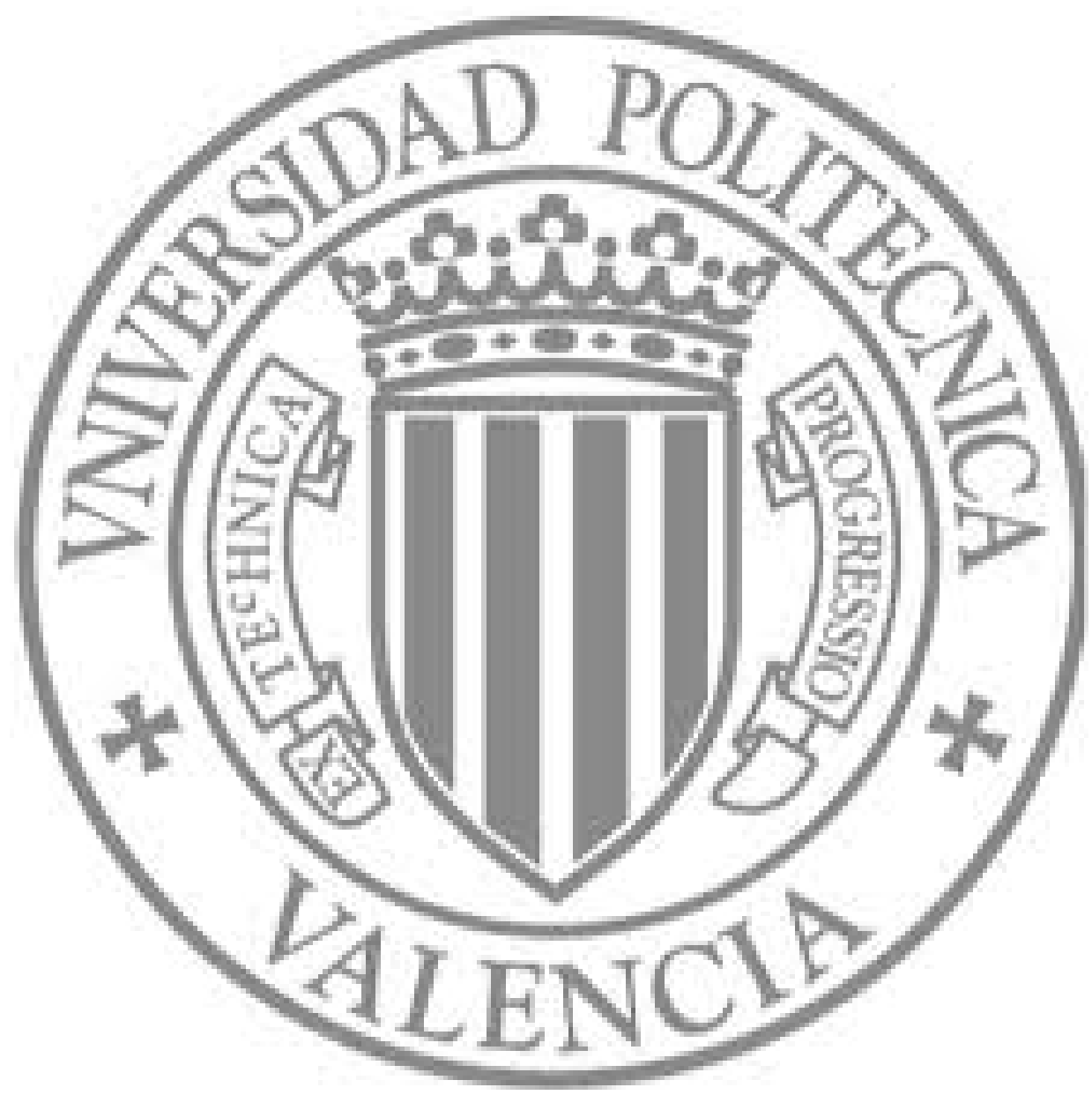

The final publication is available at

http://pubs.rsc.org/en/content/articlepdf/2011/cc/c1cc13039k

Copyright Royal Society of Chemistry 


\title{
Silica nanoparticles functionalised with cation coordination sites and fluorophores for the differential sensing of anions in a quencher displacement assay (QDA)
}

\author{
Pilar Calero, ${ }^{a, b}$ Mandy Hecht, ${ }^{c}$ Ramón Martínez-Máñez, ${ }^{* a, d, e}$ Félix Sancenón, ${ }^{a, d, e}$ Juan Soto, ${ }^{a, d}$ \\ ${ }_{5}$ José L. Vivancos ${ }^{d, f}$ and Knut Rurack*c \\ Received (in $X X X, X X X)$ Xth $X X X X X X X X X 20 X X$, Accepted Xth $X X X X X X X X X 20 X X$ \\ DOI: $10.1039 / b 000000 x$
}

In conjunction with quenching metal ions, silica nanoparticles carrying coordination sites and fluorophores were employed ${ }_{10}$ for the differential fluorometric recognition of anions.

The development of chromo- and fluorogenic chemosensors for anions has received growing interest during the past years due to the fundamental roles that anions play in chemical and biological processes. ${ }^{1}$ The majority of these chemosensors 15 incorporate molecular receptors of supramolecular chemistry design. Traditionally, supramolecular anion sensing utilizes either colour and/or fluorescence changes in probes with a "binding site-signalling subunit" architecture or undergoing chemodosimetrical reactions and indicator release in 20 displacement assays (IDAs) for signal transduction. ${ }^{2,3}$ However, recently a novel trend in chemosensor development has emerged which uses organic-inorganic hybrid materials, in many cases nanoparticles. ${ }^{4}$ These hybrid systems often show synergistic effects which are hardly achievable with molecular 25 systems or inorganic solids alone. ${ }^{5}$

Among different inorganic supports, silica nanoparticles have been extensively used for hybrid sensing materials due to their straightforward preparation and surface functionalization and high stability in aqueous suspensions. ${ }^{6}$ As an alternative 30 to chromo- and fluorogenic probes, self-assembled structures on surfaces in particular have attracted attention recently. Especially the independent functionalization of inorganic

\footnotetext{
a Departamento de Química. Universidad Politécnica de Valencia, Camino de Vera s/n, 46022, Valencia, Spain.

E-mail: rmaez@qim.upv.es

${ }^{b}$ Instituto Tecnológico de la Construcción (AIDICO), Avenida Benjamín Franklin 17, 46980, Paterna (Valencia), Spain.

${ }^{c}$ Div. 1.5, BAM Bundesanstalt für Materialforschung und -prüfung, Richard-Willstätter-Strasse 11, D-12489 Berlin, Germany.

E-mail: knut.rurack@bam.de

${ }^{d}$ Centro de Reconocimiento Molecular y Desarrollo Tecnológico (IDM). Unidad Mixta Universidad de Valencia-Universidad Politécnica de Valencia, Spain.

${ }^{e}$ CIBER de Bioingeniería, Biomateriales y Nanomedicina (CIBER-BBN), Spain.

${ }^{f}$ Departamento de Proyectos de Ingeniería, Universidad Politécnica de Valencia, Camino de Vera s/n, 46022, Valencia, Spain.

ESI

$G G G$
}

surfaces with receptor and fluorophore units is an appealing approach that overcomes the synthetic problems usually 35 immanent to the classical "binding site-signalling subunit" architecture. ${ }^{7}$ Moreover, signal amplification and cooperative binding effects associated with the independent anchoring of receptors and fluorophores in close proximity to each other and to the surface of the support are noticeable features of this 40 strategy, allowing for instance intercommunication between both subunits without the need for a direct covalent link between them. Employing silica nanoparticles functionalised with fluorophores and suitable coordination sites, this approach has recently been used for the selective recognition 45 of metal cations. ${ }^{8}$ In contrast, hybrid nanoparticles for the optical recognition of anions are much less explored. ${ }^{9}$

Our present hybrid system for the optical differential recognition of anions is based on the competitive coordination to a metal centre. Since one of our interests in such assays is 50 the facile regeneration of the sensing material, ${ }^{10}$ we modified the conventional IDA concept. Instead of displacing an indicator dye with the analyte from a binding site, which requires a two-step regeneration procedure of analyte removal and subsequent indicator reloading (and sometimes also the 55 spatial separation of indicator from the host-guest complex for detection), we attached a fluorophore (F) and a receptor (R), which does not bind to the analyte but to a mediator, separately to the support. A quenching metal ion (Q), which is at the same time a good binder for the target anion, then 60 served as the mediator, i.e., as the displaceable species, arriving at a quencher displacement assay (QDA, Scheme 1). In the first step of the protocol, the $\mathrm{R}$ units of the highly fluorescent receptor- and fluorophore-functionalised nanoparticles (RFNs) are loaded with Q, switching off the hybrid's ${ }_{65}$ fluorescence. Second, addition of the target analyte, which shows a higher affinity for $\mathrm{Q}$ than $\mathrm{R}$ does, displaces $\mathrm{Q}$ from $\mathrm{R}$, leading to revival of the fluorescence of the RFNs. In a third step, regeneration of the material is simply accomplished by reloading Q onto the RFNs. For the title material, terpyridine 70 units as $\mathrm{R}$ for the quencher metal ions $\mathrm{Q}$ and sulforhodamine $\mathrm{B}$ as signalling units $\mathrm{F}$ were independently anchored onto the surface of the silica nanoparticles.

The synthesis of the reactive precursors 1 and $\mathbf{2}$ (Scheme 1) 
and the functionalised nanoparticles is described in the ESI. The contents of terpyridine and rhodamine amount to 30.84 and $3.9 \mathrm{mmol}\left(\mathrm{mol}\left[\mathrm{SiO}_{2}\right]\right)^{-1}$ in the terpyridinesulforhodamine-functionalized nanoparticles (TSNP) and that 5 of rhodamine to $3.9 \mathrm{mmol}\left(\mathrm{mol}\left[\mathrm{SiO}_{2}\right]\right)^{-1}$ in the nanoparticles functionalized only with 2 (SNPs). Both, TSNP and SNP show a homogenous particle size of $20 \pm 2 \mathrm{~nm}$ (Fig. 1). As a rough estimate, each coated TSNP carries up to 2100 attached molecules. The average distance between two subunits thus 10 amounts to ca. $8 \AA$.
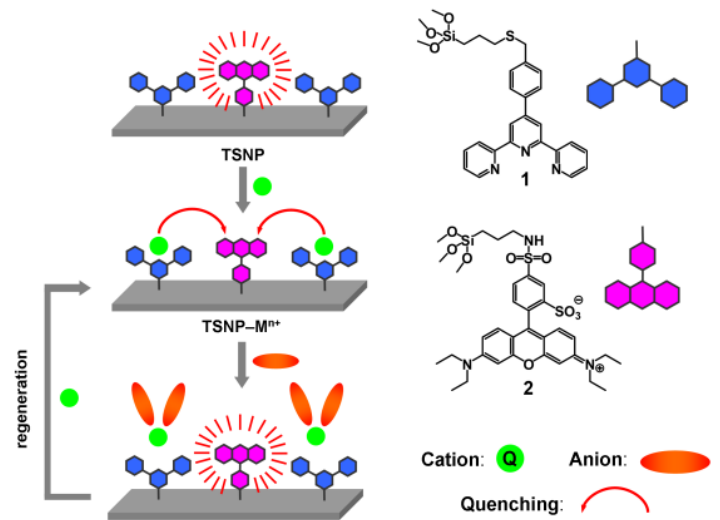

Scheme 1 Design concept of the quencher displacement assay (QDA) involving terpyridine-sulforhodamine-functionalised nanoparticles (TSNPs) and metal ion quenchers (Q).

The first step toward a successful assay is evident from the observation that the emission of the sulforhodamine fluorophore was retained after the grafting of the signalling units onto the surface of the nanoparticles. Excitation of 20 acetonitrile suspensions of TSNPs at $575 \mathrm{~nm}$ gave rise to an emission band at 580-660 nm, similar to that obtained for sulforhodamine B chloride in acetonitril (Fig. 1). Fluorescence lifetime measurements revealed that the decay times of the dye in the TSNPs $\left(\tau_{\mathrm{f}}=2.21 \mathrm{~ns}\right.$; and SNPs $\tau_{\mathrm{f}}=$ $252.21 \mathrm{~ns}$ ) is virtually identical to that of the isolated molecule in solution $\left(\tau_{\mathrm{f}}=2.24 \mathrm{~ns}\right)$, stressing the fact that the single dye molecules do not interact with eachother when attached to the surface and that grafting has also no influence on the fluorophore's properties.

30 In the second step, various heavy and transition metal ions were tested as quenchers in $\mathrm{CH}_{3} \mathrm{CN}$. In a typical experiment, suspensions of TSNP $(2.5 \mathrm{mg}$ in $20 \mathrm{~mL})$ were titrated with $\mathrm{Fe}^{3+}, \mathrm{Hg}^{2+}, \mathrm{Cu}^{2+}, \mathrm{Ni}^{2+}$ and $\mathrm{Pb}^{2+}$ (as perchlorates). As would be expected for a rather non-selective ligand, terpyridine binds 35 all these metal ions. Moreover, in all the cases, a severe quenching of 94-99\% of the rhodamine emission was found, suggesting that the average distance between $\mathrm{R}$ and $\mathrm{F}$ is sufficiently short to activate the transduction channel. Depending on the metal ion bound at the terpyridine unit, the 40 process responsible for the quenching of the dye's fluorescence involves an energy or electron transfer or enhanced spin-orbit coupling because of the heavy atom effect. $^{11}$ At saturation quenching, the major lifetime components in the complexed hybrids amount to $20-45$ ps for ${ }_{45} \mathbf{T S N P}-\mathrm{Fe}^{3+}, \mathbf{T S N P}-\mathrm{Hg}^{2+}, \mathbf{T S N P}-\mathrm{Pb}^{2+}$ and $\mathbf{T S N P}-\mathrm{Cu}^{2+}$ and $0.11 \mathrm{~ns}$ for $\mathbf{T S N P}-\mathrm{Ni}^{2+}$. In contrast to metal ions bound directly at a fluorophore, for which paramagnetic ions such as $\mathrm{Cu}^{2+}$ usually show static quenching, i.e., a non-emissive complex, and heavy metal ions like $\mathrm{Hg}^{2+}$ a complex with a 50 reduced lifetime, here, due to the separation of $\mathrm{R}$ and $\mathrm{F}$, all metal ions lead to a reduction of the lifetime of $F$, stressing the fact that a distance-dependent process is active.
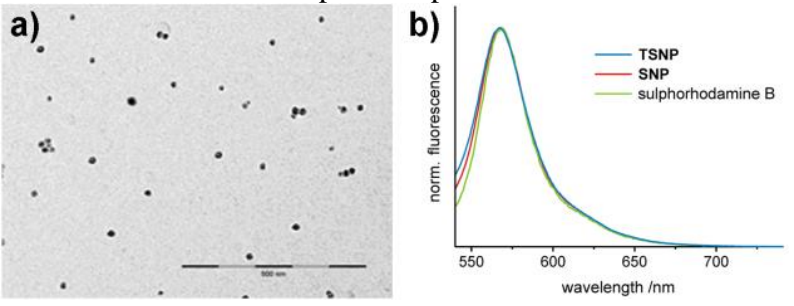

Fig. 1 a) TEM image of TSNPs, average diameter $=20 \mathrm{~nm}$; b) 55 fluorescence spectra of TSNP and SNP suspended and sulforhodamine B dissolved in acetonitrile.

The critical role of the terpyridine receptor was demonstrated in parallel studies using the model SNPs that are only ${ }_{60}$ functionalised with $\mathrm{F}$ but do not contain $\mathrm{R}$. The addition of metal ions to acetonitrile suspensions of SNPs induced negligible changes in the emission of the dye, indicating that the presence of the $\mathrm{R}$ units in SNP is critical for the quenching mechanism. Only when coordinated to terpyridine 65 are the metal ions in a spatial proximity with the fluorophore that is close enough to induce quenching.

Having established the signalling mechanism the corresponding TSNP-Q hybrid materials $\left(\mathrm{Q}=\mathrm{Cu}^{2+}, \mathrm{Fe}^{3+}\right.$, $\mathrm{Hg}^{2+}, \mathrm{Ni}^{2+}$ and $\mathrm{Pb}^{2+}$ ) were tested as sensing systems for 70 anions. The underlying idea of our approach relies on the ability of the anion to successfully compete with the terpyridine units for the metal ion and displace the latter form the $\mathrm{R}$ units, resulting in an enhancement of the fluorescence. This enhancement should be a direct consequence of a 75 delicate balance between the binding strength of the metal ion with terpyridine and the affinity of the cation for the added anion.

To test the ability of the TSNP-Q ensembles for differential recognition of small monovalent anions, 80 acetonitrile solutions of TSNP-Q chemosensors were prepared by adding 1 equivalent (with respect to the $2.0 \times 10^{-4}$ mmol $\mathrm{R}$ units contained, see ESI for details) of the corresponding metal ion to quench the rhodamine emission. Then, 0.1-10 equivalents of the anions $\mathrm{H}_{2} \mathrm{PO}_{4}^{-}, \mathrm{HSO}_{4}^{-}, \mathrm{F}^{-}$, ${ }_{85} \mathrm{Cl}^{-}, \mathrm{Br}^{-}, \mathrm{I}^{-}$and $\mathrm{NO}_{3}{ }^{-}$were added to the TSNP-Q suspensions. Except in one case (see below), no uniquely selective fluorescence changes were found. However, as a general trend the addition of $\mathrm{H}_{2} \mathrm{PO}_{4}^{-}$and $\mathrm{F}^{-}$induced a remarkable fluorescence enhancement, addition of $\mathrm{Cl}^{-}, \mathrm{Br}^{-}$and $\mathrm{HSO}_{4}{ }^{-}$ 90 induced a moderate increase of the emission whereas the addition of $\mathrm{I}^{-}$and $\mathrm{NO}_{3}{ }^{-}$induced only poor fluorescence changes. In addition, despite this general observation a clear modulation of the relative response in the presence of anions was found, depending on the metal ion employed. ${ }^{12}$ This 95 behaviour is reminiscent of other probe-metal ion-anion ternary complex systems ${ }^{13}$ and is a well-suited prerequisite for differential recognition. ${ }^{14}$ Qualitative analysis of this differential response for anions using PCA (Principal 
Component Analysis) algorithms yielded the results summarized in Fig. 2. As can be deduced from the figure, recognition patterns can be identified for all the anions studied even for those that display a rather poor change in 5 fluorescence. Fluorescence lifetime studies of the ternary systems revealed that upon addition of anions, the lifetime features of the $\mathbf{T S N P}-\mathbf{M}^{\mathrm{n}+}$ ensembles are gradually turned into the features of TSNP, i.e., the major $2.2 \mathrm{~ns}$ component of the sulforhodamine is recovered, pointing to an actual 10 displacement of the metal ion from the terpyridine units.

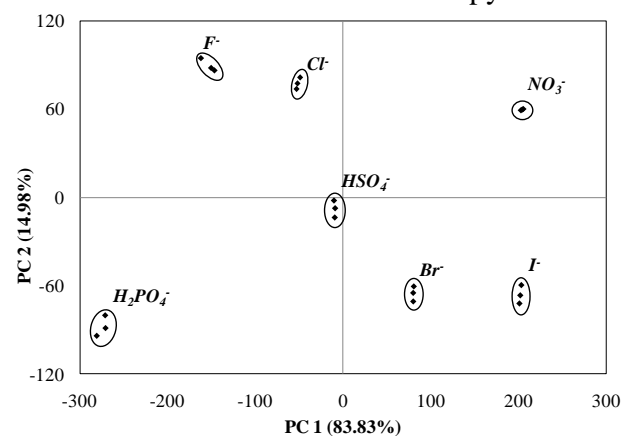

Fig. 2 Principal component analysis (PCA) score plot for the anions as indictaed using TSNP-Q $\left(\mathrm{Q}=\mathrm{Fe}^{3+}, \mathrm{Hg}^{2+}, \mathrm{Cu}^{2+}, \mathrm{Ni}^{2+}\right.$ and $\left.\mathrm{Pb}^{2+}\right)$ ensembles. Data shown from three different trials and 1:5 TSNP-Q to 15 anion ratios. PC axes are calculated to lie along lines of diminishing levels of variance in the data set.

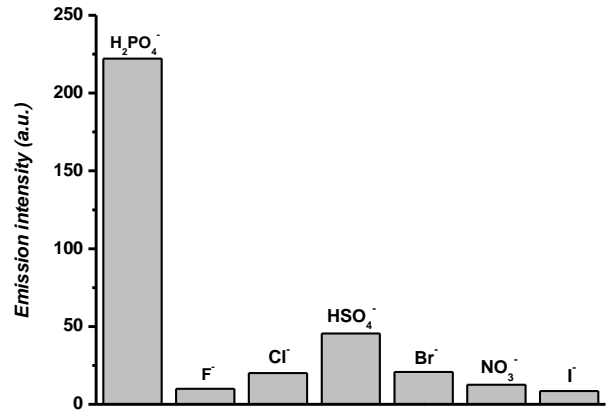

Fig. 3 Emission intensity of acetonitrile suspensions of TSNP-Pb ${ }^{2+}$ in the presence of 5 equivalents $(1.0 \mu \mathrm{mol})$ of the anions indicated.

20

Whereas the TSNP-Q systems, with $\mathrm{Q}=\mathrm{Cu}^{2+}, \mathrm{Fe}^{3+}, \mathrm{Hg}^{2+}$ or $\mathrm{Ni}^{2+}$, show a differential but no selective response in the presence of small inorganic anions, TSNP- $\mathrm{Pb}^{2+}$ behaves different, i.e., only the addition of $\mathrm{H}_{2} \mathrm{PO}_{4}{ }^{-}$revives the 25 sulforhodamine fluorescence whereas other anions remain largely passive (Fig. 3). Using this procedure, concentrations as low as 5 ppm of $\mathrm{H}_{2} \mathrm{PO}_{4}^{-}$can be detected.

A final control experiment revealed that the addition of anions to acetonitrile suspensions of TSNPs (in the absence of $\left.{ }_{30} \mathrm{Q}\right)$ or SNPs did not result in changes of the dye's fluorescence, pointing out the importance of the quenching metal ion as the mediator in the sensing paradigm. A further benefit of the system is obvious from Scheme 1. Once an analytical reaction has been performed and $Q$ displaced, 35 regeneration is easily accomplished by addition of an appropriate metal ion salt with a non-coordinating anion like perchlorate.

In summary, we have prepared a hybrid organic-inorganic sensing ensemble by grafting fluorophores and receptors onto
40 the surface of silica nanoparticles and its use in anion recognition. Coordination of metal ions at the terpyridine units induced quenching of the neighbouring fluorophores. Upon addition of anions, coordination to the metal centres and a partial recovery of the fluorescence was observed. The final 45 response of a certain TSNP-Q system to a particular anion is a delicate balance between the binding strength of the metal ion with the terpyridine and the affinity of the cation for the added anion. This allows differential recognition of small inorganic anions in a quencher displacement assay. Further50 more, regeneration of the system is possible in a straightforward manner. The facile and independent functionalisation of silica surfaces with various chemical entities and the possibile use of a number of different coordination units and metal ions make this approach highly 55 appealing for the search for new chemosensors for anions.

Financial support from the Spanish Government (project MAT2009-14564-C04-01), the Generalitat Valencia (project PROMETEO/2009/016) and the Innovationsfonds (BAM/

Bundesministerium für Wirtschaft und Technologie) is ${ }_{60}$ gratefully acknowledged.

\section{Notes and references}

1 F. P. Schmidtchen and M. Berger, Chem. Rev., 1997, 97, 1609; P. D. Beer and P. A. Gale, Angew. Chem. Int. Ed., 2001, 40, 486.

2 T. Gunnlaugsson, M. Glynn, G. M. Tocci, P. E. Kruger and F. M. 65 Pfeffer, Coord. Chem. Rev., 2006, 250, 3094; S. L. Wiskur, H. AïtHaddou, J. J. Lavigne and E. V. Anslyn, Acc. Chem. Res., 2001, 34, 963..

3 R. Martínez-Máñez and F. Sancenón, Chem. Rev., 2003, 103, 4419; M. E. Moragues, R. Martínez-Máñez and F. Sancenón, Chem. Soc. 70 Rev., 2011, 40, 2593.

4 The Supramolecular Chemistry of Organic-Inorganic Hybrid Materials, ed. K. Rurack and R. Martínez-Máñez, Wiley, 2010.

5 A. B. Descalzo, R. Martínez-Máñez, F. Sancenón, K. Hoffmann and K. Rurack, Angew. Chem. Int. Ed., 2006, 45, 5924; R. Martínez-

75 Máñez and F. Sancenón, Coord. Chem. Rev., 2006, 250, 3081.

6 R. Shenhar and V. M. Rotello, Acc. Chem. Res., 2003, 36, 549; C. Beck, W. Härtl and R. Hempelmann, Angew. Chem. Int. Ed., 1999, 38, 1297.

7 M. J. W. Ludden, D. N. Reinhoudt and J. Huskens, Chem. Soc. Rev., 2006, 35, 1122; P. M. Mendes, Chem. Soc. Rev., 2008, 37, 2512.

8 E. Rampazzo, E. Brasola, S. Marcuz, F. Mancin, P. Tecilla and U. Tonellato, J. Mater. Chem., 2005, 15, 2687; M. Crego-Calama and D. N. Reinhoudt, Adv. Mater., 2001, 13, 1171.

9 P. Calero, E. Aznar, J. M. Lloris, M. D. Marcos, R. Martínez-Máñez, 85 J. V. Ros-Lis, J. Soto and F. Sancenón, Chem. Commun., 2008, 1668; L. Basabe-Desmonts, J. Beld, R. S. Zimmerman, J. Hernando, P. Mela, M. F. G. Parajó, N. F. van Hulst, A. van den Berg, D. N. Reinhoudt and M. Crego-Calama, J. Am. Chem. Soc., 2004, 126, 7293.

9010 J. V. Ros-Lis, M. D. Marcos, R. Martínez-Máñez, K. Rurack and J. Soto, Angew. Chem., Int. Ed., 2005, 44, 4405; J. V. Ros-Lis, R. Casasús, M. Comes, C. Coll, M. D. Marcos, R. Martínez-Máñez, F. Sancenón, J. Soto, P. Amorós, J. El Haskouri, N. Garró and K. Rurack, Chem. Eur. J., 2008, 14, 8267.

9511 K. Rurack, Spectrochim. Acta, Part A, 2001, 57, 2161.

12 Higher valent anions naturally induce similar changes as verified with $\left[\left(\mathrm{CH}_{3}\right)_{4} \mathrm{~N}\right]_{2}\left(\mathrm{SO}_{4}\right)$. However, because of the significantly lower solubility of such salts in $\mathrm{CH}_{3} \mathrm{CN}$, the interference is negligible.

13 B. García-Acosta, X. Albiach-Martí, E. García, L. Gil, R. Martínez100 Máñez, K. Rurack, F. Sancenón and J. Soto, Chem. Commun., 2004, 774; B. García-Acosta, R. Martínez-Máñez, F. Sancenón, J. Soto, K Rurack, M. Spieles, E. García-Breijo and L. Gil, Inorg. Chem., 2007, 46, 3123.

14 A. P. Umali, E. V. Anslyn, Curr. Opin. Chem. Biol., 2010, 14, 685. 